\title{
Parathyroid Gland Carcinoma
}

National Cancer Institute

\section{Source}

National Cancer Institute. Parathyroid Gland Carcinoma. NCI Thesaurus. Code C4906.

A malignant tumor arising from the parenchymal cells of the parathyroid gland. It is associated with the symptoms of primary hyperparathyroidism, resulting from the excessive production of parathyroid hormone. Morphologically, the differential diagnosis from parathyroid gland adenoma may be difficult. A definitive diagnosis of carcinoma is made only in the presence of capsular invasion, vascular invasion, and/or perineural invasion. 